\title{
Prevalence Rate of Congenital Fetal Malformations in Second Trimester by Ultrasound Scanning in Zagazig University Outpatient Clinic
}

Ali El-Shabrawy Ali, Gamal Abbas El-Sayed, Basem Mohamed Hamed, Mabruka Ali Omran Tumi*

Department of Obstetrics \& Gynecology, Faculty of Medicine - Zagazig University, Egypt

*Corresponding author: Mabruka Ali Omran Tumi, Mobile: (+20)01147026222, Email: mmabrukaali@gmail.com

\begin{abstract}
Background: All pregnancies are at a risk of producing congenital malformations, though only some of them are at a greater risk. Congenital anomalies its problem in which abnormalities of structure, function or body metabolism resulting in physical or mental disability or it may be fatal.

Objective: This study aimed for early detection of major fetal anomalies to improve fetal and maternal outcome.

Patients and methods: This cross-sectional study that include 422 pregnant females was carried out at the Ultrasound Unit and Obstetrics \& Gynecology Department, Faculty of Medicine, Zagazig University during the period from December 2018 to July 2019.

Results: Ultrasonography can identify at least $35-50 \%$ of major fetal malformations with a specificity of $90-100 \%$. Though other methods of screening like biochemical markers and karyotyping are available, ultrasonography has the advantage of being non- invasive, safe, fast, accurate and reproducible with real time display, causing no discomfort to the patient at any time of gestation.

Conclusions: The Prevalence of congenital fetal malformations (CFMF) among the study participants using ultrasonography scanning was 3.6\%. The most prevalent anomalies were Hydrops fetalis and CVS anomalies. Therefore screening for congenital anomalies in obstetric sonography is an important component of primary healthcare for maternal and child health.
\end{abstract}

Keywords: Fetal malformations, Second trimester, Ultrasound scanning.

\section{INTRODUCTION}

All pregnancies are at a risk of producing congenital malformations, though only some of them are at a greater risk. There is a need for routine and thorough screening for fetal congenital anomalies. The priority goal in screening is the early detection of major fetal anomalies ${ }^{(\mathbf{1}, \mathbf{2})}$. Congenital anomalies are defined as structural defects, chromosomal abnormalities, inborn errors of metabolism and hereditary diseases diagnosed before, at, or after birth. Any deviation from the normal range during morphogenesis constitutes an anomaly ${ }^{(3,4)}$. Each year, eight million children are born worldwide with congenital anomalies, of which 3.3 million die before the age of five, 3.2 million of the survivors may be mentally and/or physically disabled. The prevalence of birth defects is comparable all over the world; about $3 \%$ in the United States, $2.5 \%$ in India and 2\% to $3 \%$ in the United Kingdom ${ }^{(5,6, \text { and } 7)}$.

Ultrasonography has emerged as one of the most powerful tools for prenatal diagnosis of congenital malformations. A second trimester anomaly scan has been suggested in routine antenatal care to increase the prenatal detection rate of fetal defects. Ultrasonography can identify at least $35-50 \%$ of major fetal malformations with a specificity of 90$100 \%$. Though other methods of screening like biochemical markers and karyotyping are available, ultrasonography has the advantage of being noninvasive, safe, fast, accurate and reproducible with real time display, causing no discomfort to the patient at any time of gestation ${ }^{(2,8)}$.
The Prevalence of abnormalities also depends upon the population being scanned. At the end an early detection of fetal anomalies has become an important part of antenatal care, by helping in identifying the severity of disease and in providing on opportunity for fetal therapy ${ }^{(9,10)}$. This study aimed to help early detection of major fetal anomalies to improve fetal and maternal outcome.

\section{PATIENTS AND METHODS}

A Cross-Sectional study include 422 pregnant women was carried out at the Ultrasound Unit and Obstetrics and Gynecology Department, Faculty of Medicine, Zagazig University during the period from December 2018 to July 2019.

Inclusion Criteria: Gestational age (GA) from 16-24 weeks. All singleton pregnant women who were referred to the Department for a second trimester complete antenatal ultrasound examination.

Exclusion Criteria: GA before 16 weeks or after 24 week. Multiple gestations. Women known to have a fetus with congenital malformation and sent for follow up.

All patients were subjected to the following : Consent to be involved in the study. Complete history taking including (age of pregnant lady, parity, date of last menstual period (LMP), positive consanguinity, history of previous baby with anomaliy, IUGR, IUFD, neonatal death, history of teratogenic drug intake or 
any exposure to imaging modality during pregnancy). Detailed ultrasound examination.

ISUOG $2^{\text {nd }}$ trimester anomaly scan.

\section{Ethical Clearance:}

Written Informed consents were taken from the women to participate in the study. Approval for performing the study was obtained from Obstetrics and Gynecology Departments, Zagazig University Hospitals after taking Institutional Review Board (IRB) approval. The work has been carried out in accordance with the code of ethics of the world medical association (Decleration of Helsinki) for studies involving humans.

\section{Statistical analysis}

Data collected throughout history, basic clinical examination, and ultrasound finding were entered and analyzed using Microsoft Excel software. Data were then imported into Statistical Package for the Social Sciences (SPSS version 20.0) software for analysis. According to the type of data, qualitative were represented as number and percentage, quantitative continues group was represented as mean $\pm \mathrm{SD}$. The following tests were used to test differences for significance: Chi square test $\left(\mathrm{X}^{2}\right)$ for difference and association of qualitative variable and differences between quantitative independent groups by test, paired by paired $t$. $P$ value was set at $\leq 0.05$ for significant results and $<0.001$ for high significant result.

\section{RESULTS}

Table (1): Prevalence of CFMF among the study participants using ultrasonography scanning

\begin{tabular}{|l|c|c||}
\hline \multirow{2}{*}{ Ultrasonography scanning } & \multicolumn{2}{c|}{$\begin{array}{c}\text { Study } \\
\text { participants } \\
\text { (n=422) }\end{array}$} \\
\cline { 2 - 3 } Normal & No. & \% \\
\hline \multicolumn{1}{|c|}{ CFMF: } & $\mathbf{4 0 7}$ & $\mathbf{9 6 . 4}$ \\
\hline - Hydrops fetalis & $\mathbf{1 5}$ & $\mathbf{3 . 6}$ \\
4 cases non immune type & 5 & 1.2 \\
1 case immune type & & \\
- CVS anomaly & 3 & 1.2 \\
- 2 VSD & & \\
- Hypoplastic left heart syndrome & 2 & 0.5 \\
- CNS anomaly & 2 & 0.5 \\
- Anencephaly & 2 & 0.2 \\
- Holo prosencephaly & 1 & \\
- Genito-urinary anomaly & & \\
- Bilateral renal agenesis & & \\
- Muscluskeletal anomaly & & \\
- Sever skeletal dysplasia & & \\
- Bilateral club foot & & \\
- Miscellaneous & & \\
- Cystic hygroma & & \\
\hline
\end{tabular}

Table (1) showed that the prevalence of CFMF among the study participants using ultrasonography scanning was $3.6 \%$. The most prevalent anomalies were Hydrops fetalis and CVS anomalies.

Table (2): Frequency distribution of parity in the study participants according to presence of CFMF

\begin{tabular}{|c|c|c|c|c|c|c||}
\hline \multirow{2}{*}{ Parity } & \multicolumn{2}{|c|}{ Normal } & \multicolumn{2}{c|}{ CFMF } & \multirow{2}{*}{$\mathbf{X}^{\mathbf{2}}$} & \multirow{2}{*}{$\mathbf{p}$} \\
\cline { 2 - 6 } & No. & $\mathbf{\%}$ & No. & $\%$ & & \\
\hline Primigravida & 232 & 57.0 & 2 & 13.3 & \multirow{2}{*}{11.2} & $\begin{array}{c}<\mathbf{0 . 0 0 1} \\
\text { HS }\end{array}$ \\
\hline Multigravida & 175 & 43.0 & 13 & 86.7 & & . \\
\hline
\end{tabular}

There was a high statistical significant association between parity of the study participants and presence of CFMF (Table 2).

Table (3): Frequency distribution of Consanguinity in the study participants according to presence of CFMF

\begin{tabular}{|c|c|c|c|c|c|c|}
\hline \multirow{2}{*}{ Consanguinity } & \multicolumn{2}{|c|}{ Normal } & \multicolumn{2}{|c|}{ CFMF } & \multirow{2}{*}{$\mathbf{X}^{2}$} & \multirow{2}{*}{$\mathbf{p}$} \\
\cline { 2 - 5 } & $\mathbf{N o .}$ & $\mathbf{\%}$ & No. & $\%$ & & \\
\hline Positive & 116 & 28.5 & 13 & 86.7 & \multirow{2}{*}{23.1} & $\begin{array}{c}<\mathbf{0 . 0 0 1} \\
\text { HS }\end{array}$ \\
\hline Negative & 291 & 71.5 & 2 & 13.3 & & . \\
\hline
\end{tabular}

Table (3) showed that there was a high statistical significant association between consanguinity in the study participants and presence of CFMF.

Table (4): Previous history of CFMF, IUGR, IUFD \& neonatal death in multigravida study participants according to presence of CFMF

\begin{tabular}{|c|c|c|c|c|c|c|}
\hline \multirow{2}{*}{ Variables } & \multicolumn{2}{|c|}{$\begin{array}{c}\text { Normal } \\
\mathbf{1 7 5}\end{array}$} & \multicolumn{2}{c|}{ CFMF 13 } & \multirow{2}{*}{$\mathbf{X}^{\mathbf{2}}$} & \multirow{2}{*}{$\mathbf{p}$} \\
\cline { 2 - 5 } & No. & $\%$ & No. & $\%$ & & \\
\hline \hline CFMF & 30 & 17.1 & 0 & 0.0 & fisher & 0.3 \\
\hline IUGR & 14 & 8.0 & 0 & 0.0 & fisher & 0.9 \\
\hline IUFD & 19 & 10.9 & 6 & 46.2 & 13.1 & $\begin{array}{c}<\mathbf{0 . 0 0 1} \\
\text { (HS) }\end{array}$ \\
\hline $\begin{array}{c}\text { Neonatal } \\
\text { death }\end{array}$ & 17 & 9.7 & 3 & 23.1 & 1.6 & 0.2 \\
\hline
\end{tabular}

Table (4) shows that there was a high statistical significant association between IUFD in the study participants and presence of CFMF.

\section{DISCUSSION}

A congenital anomaly is an abnormality of structure, function or body metabolism that is present at birth and results in physical or mental disability, or is fatal. Each year, eight million children are born worldwide with congenital anomalies, of which 3.3 million die before the age of five, 3.2 million of the survivors may be mentally and/or physically disabled (11). The prevalence of birth defects is comparable all over the world; about 3\% in the United States, $2.5 \%$ in India, and $2 \%$ to $3 \%$ in the United Kingdom. The most prevalent conditions include congenital heart defects, orofacial clefts, Down syndrome, and neural tube defects ${ }^{(\mathbf{1 2})}$. There are a number of laboratory and imaging studies available for detection of these 
anomalies. Out of these, ultrasound is the one, which gives a great amount of information about the structure and to some extent physiological aspects of the state of fetus. Some anomalies like anencephaly can be picked as early as 12 weeks when skull ossification is complete $^{(13)}$.

Routine ultrasound screening in the second trimester has been part of the maternal healthcare program in Sweden and many western countries since the 1980s. In Sweden, every pregnant woman is offered a routine ultrasound examination early in the second trimester, which is performed by specially trained midwives or doctors ${ }^{(14)}$. Initially, the main reasons for routine ultrasound examination were assessing gestational age, evaluating the number of viable fetuses and checking the placenta. Currently, screening for fetal malformations using a checklist has become an important part of the examination at the majority of obstetrical departments in Sweden (15). Prenatal detection of fetal abnormalities ranges from 17 to $85 \%{ }^{\text {(16). }}$.

All pregnancies are at a risk of producing congenital malformations, though only some of them are at a greater risk. There is a need for routine and thorough screening for fetal congenital anomalies. The priority goal in screening is the early detection of major fetal anomalies ${ }^{(\mathbf{1}, \mathbf{2})}$.

The National Health Service (NHS) Fetal Anomaly Screening Program guidance recommends screening for conditions with detection rates above $50 \%$ at this scan, including anencephaly, open spina bifida and gastroschisis. 'Defined ultrasound findings of uncertain significance' or 'normal variants' (referred to as 'markers') are also identified at this scan. These include echogenic bowel (EB), renal pelvicalyceal dilatation (PCD) and cardiac echogenic foci (CEF). Associations between markers and adverse pregnancy outcomes including intrauterine fetal death, chromosomal abnormalities and cystic fibrosis have been reported ${ }^{\left({ }^{17}\right)}$. However, many studies of markers have been conducted at specialist centers where a large proportion of pregnancies were at high-risk of adverse outcomes. Because previous studies have used inconsistent definitions of markers or provide limited details of study population characteristics, the population prevalence and clinical sequelae of markers in women at low risk of adverse pregnancy outcomes remain uncertain. As a result, guidance on the reporting and management of markers varies both within and between countries ${ }^{(\mathbf{1 8})}$.

Congenital fetal anomalies have been the concern of obstetricians and society for many centuries. A congenital fetal abnormality often results in spontaneous abortion or perinatal death, commonly associated with prematurity or major handicap including mental retardation ${ }^{(19)}$. In the present study, $30.6 \%$ of the study participants had positive consanguinity while $69.4 \%$ had negative consanguinity. $16 \%$ of the study participants had previous history of CFMF, $13.3 \%$ had previous history of IUFD, $9 \%$ had previous history of Neonatal death and only 7.4 had previous history of IUGR.

Our results showed that there was no statistical significant association between previous abortion in the study participants and presence of CFMF. There was a high statistical significant association between consanguinity in the study participants and presence of CFMF. There was a high statistical significant association between IUFD in the study participants and presence of CFMF. There was a high statistical significant association between parity in the study participants and presence of CFMF. Our results are supported by findings reported by Onyambu and Tharamba ${ }^{(20)}$ as they reported that a previous history of pregnancy with anomaly had a significant association with the occurrence of congenital anomalies. Literature has shown that most anomalies are sporadic or multifactorial, though some developmental anomalies have been found to have an underlying basis on genetics ${ }^{(21)}$. The study showed that congenital anomalies are a major cause of perinatal mortality. This compares to a Brazilian study conducted by da Silva Costa et al. ${ }^{(22)}$ on congenital malformations, which showed that odds of perinatal death were greater among those with birth defects as compared to newborns without malformations.

Naseha and Iqbal ${ }^{(23)}$ reported that family history of congenital anomaly was seen in $7.2 \%$, which is less than the incidence reported by Christianson $\boldsymbol{e t}$ al. ${ }^{(24)}$. Due to early detection of most lethal anomaly, termination was done in 35\% and IUFD occurred in $2.2 \%$. In non-lethal anomaly and a few lethal anomalies diagnosed, late early neonatal death occurred in $4.4 \%$ and late neonatal death in $0.6 \%$.

\section{CONCLUSION}

The Prevalence of CFMF among the study participants using ultrasonography scanning was 3.6\%. The most prevalent anomalies were Hydrops fetalis and CVS anomalies. Therefore screening for congenital anomalies in obstetric sonography is an important component of primary healthcare for maternal and child health.

\section{Financial support and sponsorship: Nil. Conflict of interest: Nil.}

\section{REFERENCES}

1. Sepulveda W, Cafici D, Bartholomew J et al. (2012): First-trimester assessment of the fetal palate: a novel application of the Volume NT algorithm. J Ultrasound Med., 31: 1443-1448.

2. Swetha B, Ravi G, Bharathi M et al. (2016): Evaluation of the Incidence of Congenital Fetal Malformations by Sonography in the Second Trimester. Imperial Journal of Interdisciplinary Research , 2(9): 2454-1362

3. Hata T, Hanaoka U, Tenkumo C et al. (2012): Three- and four-dimensional HDlive rendering images 
of normal and abnormal fetuses: pictorial essay. Arch Gynecol Obstet., 286: 1431-1435.

4. Santana E, Helfer T, Piassi Passos J et al. (2014): Prenatal diagnosis of a giant epignathus teratoma in the third trimester of pregnancy using three-dimensional ultrasound and magnetic resonance imaging: Case report. Med Ultrason., 16: 168-171.

5. Grisolia G, Tonni G (2013): Fetal echocardiography using HD live. J Obstet Gynaecol Can., 35: 497-498.

6. Araujo Júnior E, Nardozza L, Moron A (2013): Three-dimensional ultrasound STIC-HD live rendering: new technique to assessing of fetal heart. Rev Bras Cir Cardiovasc., 28: 5-8.

7. Grigore M, Mareş A (2013): The role of HDlive technology in improving the quality of obstetrical images. Med Ultrason., 15: 209-214.

8. Tonni G, Martins W, Guimarães Filho $\mathbf{H}$ et al. (2015): Role of 3-D ultrasound in clinical obstetric practice: evolution over 20 years. Ultrasound Med Biol., 41: 1180-1211.

9. Tonni G, Grisolia G (2013): Fetal uvula: navigating and lightening the soft palate using HDlive. Arch Gynecol Obstet., 288: 239-244.

10. Tonni G, Araujo Júnior E (2014): Three-dimensional ultrasound in obstetrics practice: myth or reality? Rev Bras Ginecol Obstet., 36: 143-145.

11. Alia N, Ahmed I, Mahais A et al. (2010): Congenital anomalies: prevalence of congenital abnormalities in 2nd trimester of pregnancy in madina teaching hospital, Faisalabad on gray scale ultrasound. JUMDC., 1: 23-28.

12. Kashyap N, Pradhan M, Singh N et al. (2015): Early detection of fetal malformation, a long distance yet to cover! Present status and potential of first trimester ultrasonography in detection of fetal congenital malformation in a developing country: experience at a tertiary care centre in India. Journal of Pregnancy, 15: $1-4$.

13. Hurt L, Wright M, Dunstan F et al. (2016): Prevalence of defined ultrasound findings of unknown significance at the second trimester fetal anomaly scan and their association with adverse pregnancy outcomes: the Welsh study of mothers and babies population-based cohort. Prenatal Diagnosis, 36 (1): 40-48.

14. Rydberg C, Tunón K (2017): Detection of fetal abnormalities by second-trimester ultrasound screening in a non-selected population. Acta obstetricia et gynecologica Scandinavica, 96 (2): 176-182.
15. Hildebrand E, Selbing A, Blomberg M (2010): Comparison of firstand second trimester ultrasound screening for fetalanomalies in the southeast region of Sweden. Acta Obstet Gynecol Scand., 89: 1412-9.

16. Besnard M, Eyrolle-Guignot D, Guillemette-Artur P et al. (2016): Congenital cerebral malformations and dysfunction in fetuses and newborns following the 2013 to 2014 Zika virus epidemic in French Polynesia. Eurosurveillance, 21 (13): 163-168.

17. Kirwan D (2010): $18+0$ to $20+6$ weeks fetal anomaly scan. In NationalStandards and Guidance for England. NHS Fetal Anomaly Screening, Pp: 1-79. https://cerpo.cl/_items/File_002_00420_0030.pdf

18. Reddy U, Abuhamad A, Levine D et al. (2014): Executive summary of a joint Eunice Kennedy Shriver National Institute of Child Health and Human Development, Society for Maternal-Fetal Medicine, American Institute of Ultrasound in Medicine, American College of Obstetricians and Gynecologists, American College of Radiology, Society for Pediatric Radiology, and Society of Radiologists in Ultrasound Fetal Imaging Workshop. J Ultrasound Med., 33: 74557.

19. Jørgensen D, Vejlstrup N, Jørgensen C et al. (2015): Prenatal detection of congenital heart disease in a low risk population undergoing first and second trimester screening. Prenatal Diagnosis, 35 (4): 325-330.

20. Onyambu C, Tharamba N (2018): Screening for congenital fetal anomalies in low risk pregnancy: the Kenyatta National Hospital experience. BMC Pregnancy and Childbirth, 18 (1): 180-84.

21. Nyberg D, McGahan J, Pretorius D et al. (2003): Diagnostic imaging of fetal anomalies. 2nd ed: Lippincott Williams and Wilkins; Philadelphia, USA. Pp: https://onlinelibrary.wiley.com/doi/epdf/10.7863/jum.2 003.22.8.850

22. da Silva Costa C, Gama S, do Carmo M (2006): Congenital malformations in Rio de Janeiro, Brazil: prevalence and associated factors. Cad Saúde Pública, 22 (11): 2423-2431.

23. Naseha A, Iqbal Y (2016): Incidence of congenital anomalies in tertiary health care centre. Journal of Evolution of Medical and Dental Sciences-Jemds, 5 (67): 4826-4833.

24. Christianson $\mathbf{R}$, van den Berg B, Milkovich $L$ et al. (1981): Incidence of congenital anomalies among white and black live births with long-term followup. American Journal of Public Health, 71 (12): 13331341. 